\title{
Letters
}

\section{Journals should select drug advertisements more carefully}

EDITOR-Until the ALLHAT study (antihypertensive and lipid lowering treatment to prevent heart attack trial) was published, ${ }^{1}$ there was little, if any, evidence of the clinical benefit of amlodipine in treating hypertension. Nevertheless, as testimony to the marketing success of Pfizer, amlodipine has become the world's biggest selling antihypertensive drug.

Pfizer is obviously keen to publicise the results from ALLHAT. Several medical journals, including the $B M J$, have recently printed an advertisement for amlodipine in which it is claimed: "with the results of the ALLHAT study, lowering blood pressure with [amlodipine] in high risk hypertensive patients is now proven to be equivalent to a diuretic in stroke outcome."

Although the advertisement is factually correct, unsurprisingly, it does not mention the comparative cost of amlodipine. According to prices in the latest British National Formulary, it costs about 16 times more to treat hypertension with amlodipine than it does with bendrofluazide, the most commonly prescribed thiazide diuretic in the United Kingdom. If equivalent efficacy is accepted, this makes amlodipine about $1 / 16$ th as cost effective. Given that hypertension is the commonest treatable chronic medical condition in the United Kingdom, a treatment strategy based on amlodipine would be wasteful.

Most would agree that those who prescribe have a duty to consider cost effectiveness, especially when there is a choice of effective treatments. ${ }^{2}$ It is therefore disappointing that major medical journals, particularly those that have championed transparency in the health service-industry partnership, are prepared to accept advertisements that contain information that may be considered misleading. We suggest that reputable journals should take account of any potentially misleading content in deciding which advertisements to publish.

James J Oliver specialist registrar in clinical pharmacology

james.oliver@ed.ac.uk

Simon R Maxwell senior lecturer in clinical pharmacology

Clinical Pharmacology Unit, Western Genera Hospital, Edinburgh EH4 2XU

Competing interests: JTO holds an educational research grant from Pfizer. SRM has no competing interests.

1 Major outcomes in high-risk hypertensive patients
randomized to angiotensin-converting enzyme inhibitor randomized to angiotensin-converting enzyme inhibitor
or calcium channel blocker vs diuretic: the Antihyperten- sive and Lipid-Lowering Treatment to Prevent Heart Attack Trial (ALLHAT).JAMA 2002;288:2981-97.

2 Gillon R. Medical ethics: four principles plus attention to scope. BMJ 1994;309:184-8.

\section{Charities and patient groups should declare interests}

EdITOR-Lenzer's news item on lay campaigners for prostate screening being funded by industry is timely. ${ }^{1}$ This serious issue of undeclared interests in commercial funding of charitable and lay organisations without apparent conflicts has recently been highlighted by both the Insulin Dependent Diabetes Trust and the Consumers Association. ${ }^{23}$

The pharmaceutical industry does not donate money to charities for altruistic reasons. It is not allowed to advertise prescription drugs to consumers, but it knows that patient groups are often a strong lobby and have power to influence government and the NHS.

Consumers trust medical charities and expect their information to be unbiased and uninfluenced by the charity's funding sources. Charities accepting industry funding should declare it as a conflict of interest to enable consumers to question their independence and that of the information they provide and seek further information from more independent sources.

Arthritis Care launched a campaign for the wider prescribing of a new COX-2 inhibitor based on misleading positive results six months into a 12 month study. It did not declare that their campaign was funded by the drug manufacturers Pharmacia and Pfizer.

The Impotence Association campaigns for wider prescription of Viagra and receives funding from Pfizer, whose logo appears on the association's website. Diabetes UK received around $£ 1 \mathrm{~m}$ from 11 pharmaceutical companies manufacturing diabetes drugs but this is not mentioned in the annual report.

The lack of acknowledgement of sums of this magnitude leads people to be suspicious. Why not simply declare the true figures to the public? What is there to hide?

Jenny Hirst co-chairman

Insulin Dependent Diabetes Trust, PO Box 294 Northampton NN1 4XS

jennyhirst@jennyhirst.co.uk

Competing interests: None declared.
1 Lenzer J. Lay campaigners for prostate screening are funded by industry. BMJ 2003;326:680. (29 March.)

2 Hirst J. Medical charities and patient groups should declare a conflict of interest. Insulin Dependent Diabetes Trust Newsletter $2003 \mathrm{Jan}: 7$

Who's injecting the cash? Which? 2003 Apr:24-5.

\section{BMJ may have hyped CURE study}

EDITOR-The 12562 patient study presented in such exciting terms as a news feature in March is none other than a reanalysis of the CURE study, which was originally published in the New England Journal of Medicine in August 2001. ${ }^{2}$ It is not a new study.

At the time of the original publication the study received immense media interest, which had the taint of marketing hype as it seemed to blow the results out of proportion. ${ }^{3}$ I'm not convinced that this Circulation reanalysis tells us much more than we knew already. ${ }^{4}$ It is important to recognise the specific licensed indication for the combination of aspirin and clopidogrelspecifically for treatment of unstable angina or non-Q wave myocardial infarction.

Has the $B M J$ unwittingly contributed to the hype?

Martin G Duerden general practitioner

Meddygfa Gyffin, Conwy LL32 8LT

martin@theduerdens.couk

Competing interests: MGD has spoken at educational meetings partly sponsored by Bristol Myers Squibb, which co-markets clopidogrel.

Spurgeon D. Combined aspirin and clopidogrel treatment improves outcomes, study finds. BMJ 2003;326:464. (1 March)

2 Clopidogrel in Unstable Angina to Prevent Recurrent Elopidogrel in Unstable Angina to Prevent Recurrent entrition addition to aspin in patients with acute coronary

National Electronic Library for Health. Heart drug that uld save 10000 lives a year. Available at: wwwnelh.nhs.uk hth/clopidogrel.asp (accessed 11 Apr 2003.)

Yusuf S, Mehta SR, Zhao F, Gersh BJ, Commerford PJ, Blumenthal M, et al. Early and late effects of clopidogrel in patiens with acute coronary syndromes Circulation 2003:107:966-72

\section{British Thoracic Society corrects damaging impression}

EDITOR-Seaton's personal view, "There's none so blind as the double blind". Discuss, is customarily amusing and challenging. ${ }^{1} \mathrm{It}$ is regrettable, therefore, that his references to the British Thoracic Society and pharmaceutical industry "sponsorship" of its guidelines are incorrect and present a picture that is both misleading and damaging.

The society does not receive funding for the preparation of its guidelines, accepting 


\section{BTS policy on guidelines}

1. Chairmen of guidelines committees should not have shares in a pharmaceutical company or be retained as a consultant with a company. Before appointment their current and recent (three years) involvement with commercial organisations will be reviewed by the chairman and three other members of the Executive Committee to ensure that there are no grounds to expect that they are likely to favour a particular product or company.

2. All members of guidelines committee should declare all commercial interests and remuneration from the biomedical industry when approached to be on the committee and when the guidelines are finalised. These should be available on the table for committee meetings and should be published at the back of the guidelines in the format adopted by the $B M J$ (ie, the type of interest but not the amount). Interests should include shares and consultancies, commercial sponsorship for the member and for the people for whom they are responsible-eg, research fellows, and support for research within their department. In the case of uncertainty the interest should be declared.

3. Members of any BTS committee who have shares or a general consultancy agreement with a biomedical company should not normally take part in discussions about any product from that company, or a main competitor, and should leave the room when such discussions occur. Members receiving a consultancy retainer for a specific product should leave the room when that product or a direct competitor is being discussed

4. The biomedical industry should not in any way finance or be involved in any aspect of developing guidelines, ie in collecting, reviewing or accessing the literature or determining the content of guidelines.

5. When guidelines are in a near final form they are often discussed at an open meeting with a wider professional group. Biomedical company support for such a meeting would be acceptable, though the chairman should confirm at the start of the meeting that anyone working for a pharmaceutical company or with a potential conflict of interest should declare this if they speak from the floor. The same principles apply if a near final version is placed on the web. Members with an interest in the pharmaceutical industry should declare that interest when they return their comments.

6. Once guidelines have been produced the biomedical industry can be involved in their dissemination and audit, including support for publications. It would be advisable for this to involve several companies.

funding only for printing and distribution costs.

Professor Seaton was one of the prime movers in producing the society's policy document about relationships with the biomedical industry (which is available on the society's website, www.brit-thoracic. org.uk) and its annual declarations of interest scheme, to which he also refers in his article. The policy is reviewed annually by the society's professional standards committee and discussed by the society's trustees and council (box).

We feel strongly that the society is in the forefront of the movement to be transparent in its dealings with industry, and we wish to correct any erroneous impressions made by Professor Seaton's article.

Edmund Neville chair, executive committee British Thoracic Society, London WC1N 2 PL edmund.neville@porthosp.nhs.uk

Competing interests: EN is chairman of the British Thoracic Society's Executive Committee.

1 Seaton A. "There's none so blind as the double blind." Discuss. BMJ 2002;326:889. (19 April.)

\section{Shared scheme for assessing drugs for multiple sclerosis}

\section{Cost effective provision of effective treatments for multiple sclerosis}

EdiTor-Sudlow and Counsell think that the UK government's risk sharing scheme for the provision of disease modifying drugs for multiple sclerosis (interferon beta and glatiramer acetate) may be flawed. ${ }^{1}$

Firstly, the risk sharing scheme was introduced to ensure that the disease modifying drugs in question are acquired by the NHS in a cost effective manner, which will be reviewed by the Department of Health at scheduled time points, with the required adjustments being made to ensure the agreed cost effectiveness threshold is maintained.

Secondly, pivotal, randomised, placebo controlled studies lasting for up to five years already show that these drugs are effective and well tolerated. The longer term outcome is less certain, although evidence both from observational studies and more than 15 years of clinical practice in the United States indicates that efficacy continues and there have been no unexpected safety issues.

We agree that additional robust long term data on lifetime cost effectiveness of treatments for multiple sclerosis need to be collected, and this is what the risk sharing scheme sets out to achieve. Crucially, cost effectiveness of treatments that delay disease progression can be measured properly only over the long term, 20 years or more. However, implying that this can only be done in a new placebo controlled study would be naive, unethical, and in practice unworkable.

Thirdly, we are surprised that unlicensed drugs or other forms of treatment are being suggested at this stage as alternatives to interferon beta or glatiramer. Azathioprine was not widely used before the disease modifying drugs were licensed, and, to our knowledge, no new data have been pub- lished in the past 10 years to suggest improved efficacy or risk-benefit profile in comparison to the licensed treatments being used in the risk sharing scheme.

Jacqueline C Napier associate medical director Schering Health Care, Burgess Hill, West Sussex RH15 9NE

jnapier@schering.co.uk

Richard Francis country manager United Kingdom and Ireland

Biogen, Maidenhead, Berkshire SL6 3UD

Glyn Wright general manager

Teva Pharmaceuticals, High Wycombe, Buckinghamshire HP13 7SS

Competing interests: The authors are employees of pharmaceutical companies involved in multiple sclerosis research and the risk sharing scheme

1 Sudlow CLM, Counsell CE. Problems with the UK governsclerosis. BMJ 2003;326:388-392. (15 February.)

\section{Dealing with uncertainties about cost} effectiveness of treatments is difficult problem

EDITOR-Sudlow and Counsell argue for a trial comparing disease modifying treatments with azathioprine, and placebo as an alternative to the risk sharing scheme, which they believe to be scientifically unsound. ${ }^{1}$ As independent scientific advisers to the scheme we would like to correct some inaccuracies.

Firstly, patients who have already been prescribed disease modifying treatments will not contribute to the main analyses of cost effectiveness.

Secondly, subjects will be followed up irrespective of compliance to allow intention to treat analyses.

Thirdly, there are no obviously better alternatives to the expanded disability status score. A quality assurance protocol is being developed, including further validation of the status score against cost utilities. Blinded assessments are unhelpful without a concurrent control group.

Fourthly, other series of patients with multiple sclerosis will be used to validate the Canadian historical control cohort.

Finally, the scheme has approval from the multicentre research ethics committee and includes resources for extra staff to collect data.

How best to deal with uncertainties about cost effectiveness of treatments is a difficult problem, particularly in chronic, disabling, neurological conditions where no other effective treatments exist. Industry sponsored licensing studies often leave important unanswered questions about clinical benefits. In retrospect, it is regrettable that the independent UK trial of cost effectiveness, proposed when the drugs were first licensed, was not funded and speedily implemented. Now that their use has become entrenched, denying patients the treatment until greater precision becomes available many years hence has become socially and politically unacceptable.

The scheme is a compromise to make the treatments available by sharing the financial burden with industry. Although it will not provide a reliable estimate of clinical 
effectiveness, it will deliver a high level of audit of outcome. Moreover, the risk sharing scheme should not be incompatible with Sudlow and Counsell's proposed trial. It may be too late, however, to include a placebo arm, as this is unlikely to be supported by clinicians or patients.

David Chadwick professor of neurology

Walton Centre for Neurology and Neurosurgery,

University of Liverpool, Liverpool L9 7LJ

dwc@liv.ac.uk

Richard Gray professor of statistics

Birmingham Clinical Trials Unit, University of

Birmingham, Birmingham B15 2TT

Competing interests: None declared.

1 Sudlow CLM, Counsell CE. Problems with the UK government's risk sharing scheme for assessing drugs for multiple sclerosis. BMJ 2003;326:388-392. (15 February.)

\section{Why are eyes tightly shut to considering} causes other than autoimmunity?

EDitor-We agree with Sudlow and Counsell that the evidence for the risk sharing scheme for interferon beta and glatiramer in multiple sclerosis is poor. ${ }^{1}$ There are serious clinical and scientific flaws in advocating immunological treatments for multiple sclerosis. ${ }^{2}$ Before committing precious resources to any trial involving several thousand patients as proposed ${ }^{1}$ we have to be clear about the primary end point. In our view, it can only be the prevention of long term disability rather than reduction of short term fluctuations related to relapses.

Progressive neurological disability in multiple sclerosis is due to neuronal loss. Widespread axonal damage is always present even at the earliest clinical stages of the disease and is independent of the inflammatory changes.' Multiple sclerosis is not an autoimmune disease and experience has shown that azathioprine is not effective. Investing in a long term randomised trial of "interferon beta or glatiramer versus azathioprine versus no treatment" will be as wasteful as the current risk sharing scheme. ${ }^{1}$ This is for several reasons, not the least being the characteristic side effect profiles of the individual treatments that will limit effective double blinding, a fact recognised in the Cochrane review of the interferon beta trials.

Future treatment trials should be based on metabolic strategy and neuroprotection. ${ }^{2}{ }^{3}$ Rather than looking for small effects in a large trial, an alternative, which historically has proved more effective, will be to invest in small trials of many treatments looking for large effects. ${ }^{4}$ Why are we keeping our eyes so tightly shut in not looking for treatment for multiple sclerosis beyond autoimmunity?

Abhijit Chaudhuri senior lecturer in clinical neurosciences

ac54p@udcf.gla.ac.uk

Peter O Behan emeritus professor of neurology,

University of Glasgow

Department of Neurology, Institute of Neurological Sciences, South Glasgow University Hospitals NHS Trust, Glasgow G51 4TF

AC is supported by the Barclay Research Trust in the University of Glasgow.

Competing interests: None declared.
1 Sudlow CLM, Counsell CE. Problems with the UK government's risk sharing scheme for assessing drugs for multiple chers sor

Per PO, Cha Behan PO, Chaudhuri A, Roep BO. Pathogenesis of multiple sclerosis revisited. JR Coll Phys Edinb 2002;32:244-65. Fillipi M, Bozzali M, Rovaris M, Gonen O, Kesavadas C Ghezzi A, et al. Evidence for widespread axonal damage at he earliest clinical stage of multiple sclerosis. Brain

4 Horrobin DF. Effective clinical innovation: an ethical imperative. Lancet 2002;359:1857-8.

\section{Doctors and managers}

\section{NHS needs political administration, not} "management"

EDITOR-Davies et al report the views of doctors and managers on their relationship in the NHS. ${ }^{1}$ My objectives as a clinical director are to achieve the best balance between cost, quantity, and quality of health care. NHS managers' objectives are to "balance" expenditure on health care against an inflexible and unpredictable income stream and to satisfy political demands.

We have no common goal. The current political obsession with improving efficiency of the NHS through better management is misdirected.

Demand for health care is infinite. Resources are limited. We need politicians with the courage and insight to decide the boundaries for NHS care: until they do so, more money spent on "managing" the NHS is simply wasted.

Politicians should define a clear common goal for clinicians and managers and let us work together to achieve this.

Richard Motley clinical director

University Hospital of Wales, Cardiff CF14 4XW RJMotley@msn.com

Competing interests: None declared.

1 Davies HTO, Hodges CL, Rundall TG. Views of doctors and managers on the doctor-manager relationship in the NHS. BMJ 2003;326:626-8. (22 March.)

\section{NHS is unmanageable corporate mess}

EDITOR-Conflict between doctors and managers results from the NHS's unmanageability. ${ }^{12}$ Corporate governance requires that product, strategy, customer, and shareholder are clearly identified, but the NHS's product and strategy are dictated externally and changed daily by politicians, patients, managers, media, royal colleges, pressure groups, health professionals (including doctors), employees, Europe, and lawyers.

These make ever burgeoning demands for products that include health provision, disease management, illness prevention, death postponement, social engineering, lifestyle improvement, transport, education, and board and lodging, and the NHS seems powerless to refuse.

Smith is incorrect-patients are not customers. ${ }^{2}$ The purchaser is the customer, and NHS patients are manifestly not purchasers. The government is the paying customer, demanding target hitting satisfaction, but it is also the sole shareholder providing the investment and appointing the boards. Is this corporate governance?

The NHS is an unmanageable corporate mess. Doctors see the effects of this and blame the managers. Hence the conflict.

Peter G Hope consultant orthopaedic surgeon Lister Hospital, Stevenage, Hertfordshire SG1 4AB peter.hope@which.net

Competing interests: None declared.

1 Edwards N, Marshall M, Mclellan A, Abbasi K. Doctors and managers: a problem without solution? $B M J$ 2003; 326:609-10. (22 March)

2 Smith R. What doctors and managers can learn from each other. BMJ 2003;326:610-1. (22 March.)

Capacity and funding need to be increased

EDITOR-It would be useful for doctors and managers to behave at times of pressure more reasonably towards one another and to try to appreciate and understand the other group's perspective of a problem. ${ }^{1}$ However, finding a solution to why doctors and managers have been in disagreement for around 50 years perhaps is addressing the wrong problem. ${ }^{2}$

There is a greater communication and misunderstanding problem between health services and the public than there is between doctors and managers. This imposes the greatest pressure on the NHS. Better, repeated, honest, and open public education by doctors and managers about the abilities and limitations of the NHS in its present form is required so as to counter public misperceptions and expectations fuelled by the Department of Health and the media Fulfilling realistic public expectations will only happen once increases in capacity and funding have made more of an impact on a chronically underfunded service.

Nigel Dudley consultant in elderly medicine St James's University Hospital, Leeds LS9 7TF nigel.dudley@leedsth.nhs.uk

Competing interests: ND is trying to deliver a stroke service without any additional funding specifically targeted at the hospital or community elements of the stroke section of the NHS and not being able to meet his own expectations for patients.

1 Edwards N, Marshall M, Mclellan A, Abbasi K. Doctors an managers: a problem without solution? BMJ 2003; managers: a problem

2 Hospital administration in the NHS (editorial). BMJ 1955;ii:609-10.

Successful partnerships in New Zealand have been incorrectly portrayed

EDITOR-As a practising clinician in New Zealand, I was interested to read the New Zealand perspective on the managementclinician interface in the article by Malcolm et al. ${ }^{1}$ However, even after several careful readings I was totally unable to relate it to my experience or that of my local general 
practitioner colleagues or (I presume) the hospital consultants in nearby Timaru, who have recently been driven to strike action.

The sad reality is that with ongoing health "reforms" being driven through in a Machiavellian fashion, clinical morale here in New Zealand is lower than for decades, leading to a crisis in recruitment and retainment of medical staff.

Unfortunately, this purportedly authoritative article was written by a group composed of neither clinicians nor managers, and it was almost entirely self referenced. These self styled experts have created a very rosy picture, but do not be fooled-the reality here is of a divide between clinicians and management that is as wide as ever.

Sally M Widdowson general practitioner

Sumner Health Centre 35, Nayland Street,

Christchurch, New Zealand 8008

paul.corwin@chmeds.ac.nz

Competing interests: None declared.

1 Malcolm L, Wright L, Barnett P, Hendry C. Building a successful partnership between management and clinical leadership: experience from new Zealand. $B M J$ 2003;326:653-4. (22 March.)

\section{What is the evidence base for management?}

EDITOR-I enjoyed reading the papers on doctors and managers. ${ }^{1}$ Improved mutual understanding could benefit the NHS, but underlying all the papers is an assumption that the current style of management of the health service is necessary.

Evidence shows that centralising management of health organisations is wasteful of resources and has no beneficial impact on outcomes for patients. Bickman et al have shown in several case-control studies that centralising the management of child and adolescent mental health services results in greater costs and no improvement in child and adolescent mental health. ${ }^{2}$ If this were true for a medical intervention would we continue to offer it?

The solution may lie in a different model of management. My experience of general practice management implies that it is possible for the clinical staff to remain in senior manager roles while the practice manager enables their work to proceed effectively and efficiently.

Tim I Williams consultant clinical psychologist Berkshire Healthcare NHS Trust, Wokingham Hospital, Wokingham RG41 2RE sxswiams@rdg.ac.uk

Competing interests: None declared.

1 Improving the doctor-manager relationship. BMJ 2003;326:652-4. (22 March.)

2 Bickman L, Lambert EW, Andrade AR, Penaloza RV. The Fort Bragg continuum of care for children and adolescents: mental health outcomes over 5 years. J Consult

\section{Commission for Health Improvement gives its perspective}

EdIToR-The increasing involvement of doctors in medical management ${ }^{1}$ has been justified by the beliefs that doctors are more aware of the clinical implications of corporate decisions, and that other doctors are more likely to accept managerial decisions from another doctor. These beliefs, if true, would be apparent to an review team with evidence of:

- Good team working within and between departments

- Good communications between staff and management

- Involvement of medical staff in strategic decisions, and

- Progress in involving all staff in implementing clinical governance.

There is as yet no objective evidence linking good relationships between doctors and managers with better quality care for patients. However, during 250 clinical governance reviews, the Commission for Health Improvement (CHI) has shown the converse-that when there have been serious service failures, or when organisations have scored poorly in many components of clinical governance, there is often poor team working, lack of clinical leadership, or poor relationships between doctors and managers.

Linda Patterson medical director

linda.patterson@chi.nhs.uk

Nicholas L Bishop assistant medical director Commission for Health Improvement, London EC1Y 8TG

Competing interests: None declared.

Editor's choice. Vive la différence? BMJ 2003;326(7390):0. (22 March.)

\section{Clear strategy is needed, as Turkish} experience shows

EDITOR-Doctors and managers share a common goal: patients' health. Doctors focus on patients' ultimate wellness regardless of cost. Managers focus on systems securing patients' access to health considering limited resources. These views complement each other.

At Baskent University Hospital, Turkey, we believe that a well functioning doctormanager relationship delivers real service improvements.

Firstly, we develop vision, mission, and goals with patients' wellbeing central to our deliberations.

Secondly, we define and map critical processes for hospital departments and create quality improvement teams. Managers, doctors, and nurses participate in these teams, which set priorities, develop healthcare indicators, and propose outcomes for programme evaluation. We hope for a system that responds to patients' needs, operates on evidence based standards, reduces medical errors, contains costs, and in which we are all accountable.

Finally, commitment and a clear strategy supported by top management transforms the relationship between doctors and managers into a win-win situation: collaboration. ${ }^{23}$

Seval Akgün professor of public health sevala@baskent-ank.edu.tr

Guillermo Herrera guest researcher Public Health Department, Faculty of Medicine, Baskent University, 06490 Bahcelievler, Ankara, Turkey

Competing interests: None declared.
1 Davies HTO, Harrison S. Trends in doctor-manager relationships. BMJ 2003;326:646-9. (22 March.)

2 Smith $R$. What doctors and managers can learn from each other B. BJ 2003:326:610-1. (22 March)

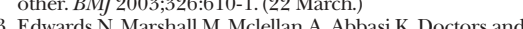
Edwards N, Marshall M, Mclellan A, Abbasi K. Doctors an managers: a problem without solution? BMJ 2003;326:
609-10. (22 March.)

\section{Healthcare management is treated as} specialty in Israel

EDITOR-The ongoing debate on doctors and managers reflects the low regard doctors are held in as managers. ${ }^{1}$ In Israel healthcare management is a specialty, awarded as a diploma.

A doctor may get this diploma from the Ministry of Health after a long preparation period, which includes completing an MD degree, training (residency) in a clinical specialty, a master's degree in business or healthcare administration, two years of practical supervised training in health administration, and two examinations (written and oral). Among some 17000 doctors, about 25 candidates each year apply for the training programme, which is provided by several academic centres in Israel.

These highly motivated doctors wish to become leaders in health care, and more doctors in administrative positions now know what clinical work is all about. Concurrently academic and on the job training programmes have been developed for people without an $\mathrm{MD}$ in the healthcare system.

In our organisation we run joint training programmes for both categories of managers, as well as for nurses with academic degrees. With these training programmes and close contacts between managers with different backgrounds the barriers between clinical practice and managers should dissolve.

Dan Michaeli chairman, board of directors

Clalit Health Services, 101 Arlozorov St, Tel Aviv, Israel 62098

michaeli@clalit.org.il

Competing interests: None declared.

1 Atun RA. Doctors and managers need to speak a common language. BMJ 2003;326:655. (22 March.)

\section{Discrimination in discretionary points award scheme}

\section{Premise is flawed}

EDITOR-Esmail et al in their paper on discrimination in the discretionary points award scheme say that they assessed whether any disparity was associated with ethnic origin and sex. ${ }^{1}$ They concluded that non-white and female consultants may be disadvantaged under the (present) award scheme. Their paper has not shown this.

They looked superficially at ethnic group and sex, with no evidence of causation. To prove their premise, they would have had to show that other relevant factors were equal; other factors deserving consideration might be hours actually worked on behalf of the NHS per week, or emotional intelligence (which is related to job success ${ }^{2}$ ). 
With the advent of scoring systems now widely used in awards, there is perhaps good reason to check that applicants with equal scores were not disadvantaged by sex or ethnicity. That is what this paper could have done, and such an analysis would be valuable as an audit.

An analysis as superficial as presented in this paper however does no service to the medical profession or to those attempting to reward fairly those who have gone the extra mile in the service of the NHS.

Alastair Lack consultant anaesthetist

Salisbury Hospital, SP2 8B]

jal@scata.org.uk

Competing interests: None declared.

1 Esmail A, Abel P, Everington S. Discrimination on the discretionary points award scheme: comparison of white with
non-white consultants and men with women. BMJ non-white consultants and men with women. BMJ
2003:326:687-8. (29 March.) 2003;326:687-8. (29 March.)

McMullen B. Career focus. Emotional intelligence. BMJ 2003;326(suppl):S19. (18 January.)

\section{Discretionary points have to be applied for}

EDITOR-By using as their denominator figure the number of consultants eligible for discretionary points, Esmail et al introduce a flaw to their hypothesis.

Not all eligible consultants apply for discretionary points. Those that do not apply will not be considered and will not receive them. Their finding that non-white and female consultants have fewer points could be because more of these categories do not apply for them.

Bill Cave consultant anaesthetist

Nevill Hall Hospital, Abergavenny NP7 7EG Cavburnie@aol.com

Competing interests: None declared.

1 Esmail A, Abel P, Everington S. Discrimination on the discretionary points award scheme: comparison of white with non-white consultants and men with women. $B M J$ 2003;326:687-8. (29 March.)

\section{Walk-in centres are often first line contact for rape victims}

EDITOR-Wilken and Welche discusssed the management of people who have been raped. ${ }^{1}$ Walk-in centres provide emergency hormonal contraception: we see women presenting for emergency hormonal contraception because they have been raped.

Victims include people who have experienced "date rapes" or domestic violence-not everyone feels able to divulge the circumstances of their experience. Amazingly, some do not even realise that they have been raped. Few want police involvement.

Walk-in centres could, in the future, take samples for blood and urine 0-72 hours after the rape (for drugs), which is also the time frame for post-traumatic reactions and administration of emergency contraception.

Walk-in centres offer long opening hours, treatment of minor injuries, and drug treatment under primary group direction on site. Staff also have access to other relevant areas via liaison links and referral pathways. Walk-in centre nurses could even be trained in forensic and sexual health examination. There is currently a nurse forensic examiner pilot scheme in Manchester.

The recent changes to the rape laws to encourage reporting of this crime are likely to affect the NHS-the 42 walk-in centres countrywide could help improve the quality of care currently offered to this client group Maria J Gough

walk-in centre nurse practitioner

Harlow NHS Walk in Centre, Harlow, Essex

CM20 1QO

tabbs44@hotmail.com

Competing interests: None declared.

1 Wilken J, Welch J. Management of people of have ben raped. BMJ 2003;326:458-9. (1 March.)

\section{GMC guidance on withholding life prolonging treatment}

EDITOR-Kmietowicz reports that advice on withholding food and water breaks the law. ${ }^{1}$ The GMC's guidance does not allow doctors to withdraw food and water from patients with the intent of causing or hastening their death (www.gmc-uk.org/standards). We believe such actions to be unlawful and unethical.

The guidance covers the situation where-while a patient's death is not imminent-a doctor may judge that the patient's condition is so severe and the prognosis so poor that providing artificial nutrition or hydration may cause suffering or be too burdensome for the patient in relation to the possible benefits. A decision to withhold or withdraw artificial nutrition or hydration may be made in these cases only:

- After a full assessment has been made of the patient's individual requirements and the possible means of providing nutrition and hydration-for example, by nasogastric tube, subcutaneous hydration, or intravenous cannula

- After a full consultation with the healthcare team and those close to the patient

- After a second opinion from a senior clinician who is not already directly involved in the patient's care has been sought (approval of a court is needed where the patient is in persistent vegetative state).

The guidance was drafted after extensive consultation with medical, patient, human rights, religious, and other groups. We also sought advice from the official solicitor and other experts in medical law. We believe that the guidance is consistent with the law and takes into account recent judgments, including those relating to article 2 of the European Convention on Human Rights.

Our guidance provides a framework to help doctors assess patients' individual needs and circumstances, and respond to them, making decisions in the best interests of patients.

Hilary Thomas chair, standards committee General Medical Council, London W1N 6JE jobrien@gmc-uk.org

Competing interests: None declared.
1 Kmietowicz Z. Advice on withholding food and water breaks the law. BMJ 2003;326:780. (12 April)

\section{Bioethics are difficult to balance}

EDITOR-Singh and DePellegrin focus too narrowly on the Western notions of bioethics. ${ }^{1}$ According to them, doctors who permit images of war to be captured fail in their legal and ethical duty to protect their patients.

Bioethical codes may not be different around the world, but they have to be contextual. Preaching to doctors not to allow filming of injured people in wars without consent is adding further insult to their injuries. Is the value of confidentiality and privacy more at stake here or the issues of justice and human rights? Would it be ethical for the doctors to censor the plight of civilian victims of war? In public health, individual rights can be usurped for the benefit of larger community. Why in a war, where there is danger to millions, should individual rights be so sacred?

In this day and age it is equally crucial to win the war on the electronic front as it is to win on the battleground. Special "embedded" journalists showed what they wanted the Western world in particular to see-the backdrop of upbeat music was of an army marching among the fallen defending soldiers, with the deafening blitz of heavy artillery and the roar of rolling armour as liberators of a sovereign state.

Other journalists braved it out where cruise missiles rained relentlessly. Should they have shown the fireworks and illuminations on the skies or the casualties of war? I wonder as a doctor working in these conditions, would it not be ethical for me to allow the world to see the horrific images of war? The realities of war are bitter, and the realisation of it necessary and absolute. Ethically it is equally important to try to stop or prevent such catastrophe as it is to treat victims of war with respect.

Asad J Raja associate professor

Department of Surgery, Aga Khan University,

Stadium Road, Karachi, Pakistan 74800

asad.raja@aku.edu

Competing interests: None declared.

Singh JA DePellegrin J. Images of war and emdical ethics. BMJ 2003;326:774-5. (12 April.)

\section{Correction}

Medical experts and the criminal courts

Owing to an editorial error the surname of the author of the second letter in this cluster was misspelt (10 May, p 1037). The author's name is Neville Davis [not Neville Davies as published].

\section{bimj.com}

Letters appearing here are an edited selection of rapid responses originally posted on bmj.com

We ask for all letters to the editor to be submitted as rapid responses via bmj.com

For advice see: bmi.com/rapidresponses 